Article

\title{
High-Precision Speed Control Based on Multiple Phase-Shift Resonant Controllers for Gimbal System in MSCMG
}

\author{
Jian Feng ${ }^{1}$ (), Qing Wang ${ }^{2}$ and Kun Liu ${ }^{1, *}$ \\ 1 College of Aerospace Science and Engineering, National University of Defense Technology, \\ Changsha 410073, China; fengiian@nudt.edu.cn \\ 2 Shanghai Institute of Spaceflight Control Technology, Shanghai 210011, China; wqing@mail.ustc.edu.cn \\ * Correspondence: liukun_nudt@163.com; Tel.: +86-731-8457-4194
}

Received: 16 November 2017; Accepted: 19 December 2017; Published: 1 January 2018

\begin{abstract}
The high precision speed control of gimbal servo system in magnetically suspended control moment gyro (MSCMG) suffers from periodic torque disturbances, which lead to periodic fluctuations in speed control. This paper proposes a novel multiple phase-shift resonant controller (MPRC) for a gimbal servo system to suppress the periodic torque ripples whose frequencies vary with the operational speed of the gimbal servo motor and high-speed motor. First, the periodic torque ripples caused by cogging torque, flux harmonics and the dynamic unbalance of the high speed rotor are analyzed. Second, the principle and structure of MPRC parallel with proportional integral (PI) controllers are discussed. The design and stability analysis of the proposed MPRC plus PI control scheme are given both for the current loop and speed loop. The closed-loop stability is ensured by adjusting the phase in the entire operational speed range. Finally, the effectiveness of the proposed control method is verified through simulation and experimental results.
\end{abstract}

Keywords: gimbal servo system; magnetically suspended control moment gyro; periodic torque ripples; multiple phase-shift resonant controllers

\section{Introduction}

Magnetically suspended control moment gyro (MSCMG) has been considered as an indispensable inertial actuator for the attitude control of agile maneuver satellites due to its high-precision, long life and large output torque generation [1-4]. Single gimbal MSCMG gimbaled in one axis only, consists of a high-speed rotor system and a gimbal servo system, as shown in Figure 1. The rotor system, which is suspended by magnetic bearing, generally operates at a high constant speed to supply the demanded angular momentum $H$. The gyro torque is the output to adjust the spacecraft attitude when the direction of the angular momentum is changed by the rotation of the gimbal servo system. The output torque can be expressed as $M=H \times \omega$, where $\omega$ is the angular speed of the gimbal servo motor. It is obvious that high-precision angular speed-tracking performance of the gimbal servo system must be achieved to ensure the accuracy of the MSCMG output torque.

A permanent magnet synchronous motor (PMSM) is applied in the gimbal servo system for a MSCMG due to its distinct advantages of high power density and efficiency, compactness and ease of control. Generally, in order to achieve high performance, the gimbal servo system is directly driven by a PMSM without gear drive [5]. The gimbal servo system is an ultra-low-speed mechanical servo system, and the speed range of the research object in this paper is $-2 \mathrm{rad} / \mathrm{s}$ to $2 \mathrm{rad} / \mathrm{s}$. 


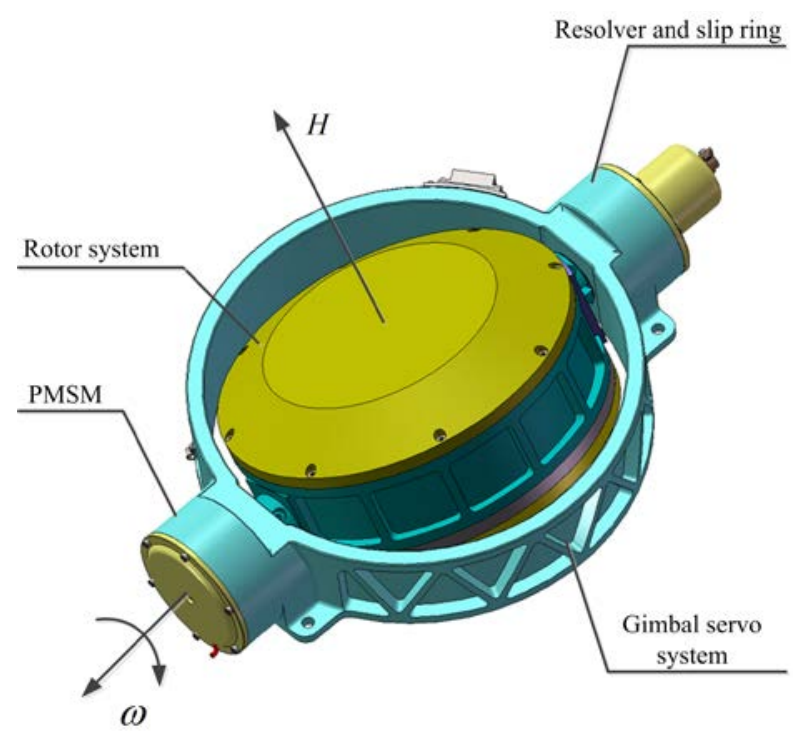

Figure 1. Schematic diagram of the single gimbal CMG.

The main factors affecting the gimbal servo system performance include friction torque, inherent torque ripples in the PMSM and other external torque disturbances. Various algorithms have been proposed for friction torque compensation [6-10]. A model-free control method with an elasto-plastic friction observer is proposed in [7] and an adaptive friction compensation scheme is proposed in [8]. However, general friction compensation cannot fully inhibit the friction torque in an MSCMG gimbal system due to the gyroscopic effect [9]. Methods based on time delay control and internal model control [9] and methods based on a cascade extended state observer [10] are presented for the friction compensation of gimbal servo systems in double gimbal control moment gyro (DGCMG). However, the influence of inherent torque ripples and other external torque pulsations, especially the torque ripple caused by high-speed rotor systems, are not investigated.

Regardless of the PMSM, torque pulsations come from various sources, and they can be attributed to cogging torque, flux harmonics and errors in current measurements [11-20]. Among these, the former two factors are often the main causes of the poor control precision of PMSMs. Broadly speaking, the techniques for torque ripple suppression can be divided into two categories. The first approach focuses on the optimal design of PMSM [11,12] and inhibits torque ripples by means of skewing the stator slots or rotor poles. Nevertheless, there are many occasions in which these methods are not sufficient to eliminate torque ripples. The second group of techniques, which is our interest, emphasizes various control algorithms of stator currents [13-20]. These approaches include model predictive control (MPC) [13,14], artificial control [15], iterative control [16], repetitive control [17], and so on. A cascade -MPC method [13], and an MPC and extended state observer based approach [14] are presented to suppress torque ripple and optimize the control performance of the PMSM servo system. Reference [15] proposes a self-learning solution based on artificial neural networks to reduce the torque ripple in a permanent-magnet nonsinusoidal synchronous motor. The abovementioned approaches improve the performance of the PMSM from different aspects. However, they all suffer from the disadvantage of complex computation.

Both the torque pulsations that come from cogging torque, flux harmonics and the torque ripple inherited from high-speed rotor systems vary periodically, which make periodic control techniques naturally suited to this situation. Compared with iterative controllers [16] and repetitive compensations [17], resonant controllers (RCs) have become one of the most popular periodic disturbance rejection methods due to their advantages of simplicity, relatively simple turning process and easy frequency adaptation [18-25]. RCs are widely used in power systems to suppress harmonic disturbances [18-21]. In [18-20], RCs are used for current control in grid-connected converters. In [21], 
the torque ripple is inhibited by multiple RCs in a doubly-fed induction generator-direct current (DFIG-dc) system and positive results have been obtained. However, RCs used in power systems are usually tuned to a single frequency and achieve excellent performance only in a narrow frequency range. This narrow frequency range is unsuitable for a gimbal servo system in MSCMG, whose torque ripple frequencies vary with their operation speed. RCs are also introduced for torque ripple suppression in PMSM control [22-25]. In [22], RC is implemented in the stationary frame, which makes it quite resource consuming, as online trigonometric computation is needed. Reference [23] optimizes the implementation of RCs by designing the controller in a synchronous reference frame, and this improvement permits the reduction of the number of RCs and the computation burden. In [24], a technique for the torque ripple minimization of PMSMs using a proportional RC is proposed. However, they all report preliminary simulations and experimental results and do not include any discussion of the tuning process of the controller. Reference [25] develops a cascade proportional integral RC structure for a low-speed, high-torque PMSM with a current and speed control as the inner and outer loops. This method can only work in a specific steady-state as its resonant frequencies are designed according to the speed reference. Moreover, the parameter tuning of the RCs is complicated in [25].

To overcome the drawbacks of the aforementioned RC schemes, a multiple phase-shift resonant controller (MPRC) is proposed to suppress the periodic torque ripples of the gimbal servo system at variable speed. Compared with the previous schemes, the novelty of this paper mainly contains the following three aspects:

(1) Torque ripples caused by high-speed rotor dynamic imbalance in a gimbal servo system for MSCMG are first discussed and modeled.

(2) The absolute closed-loop stability and robustness of the overall system is ensured by the proposed MPRC approach and the phase angle is adjusted for wide and multiple resonant frequency-varying conditions.

(3) The design and tuning processes of the MPRC are discussed and simplified. These are important and practical, especially for a gimbal servo system with multiple frequency RCs both in current and speed control loops.

This paper is organized as follows. In Section 2, the dynamic modeling and disturbance analysis of a gimbal system are presented. In Section 3, the MPRC is designed for current and speed controllers to suppress multiple frequency components of torque disturbance simultaneously. Section 4 provides the simulation and experimental results to validate the effectiveness of the proposed scheme. Section 5 provides the conclusion.

\section{Dynamics Modeling and Periodic Disturbance Analysis of Gimbal System}

\subsection{Model of Gimbal Servo System}

Assume that the PMSM iron core is unsaturated and the hysteresis and the eddy current loss are ignored. In the synchronous reference $d-q$ frame, the model of the surface mounted PMSM can be written as follows

$$
\left\{\begin{array}{c}
\frac{d \omega}{d t}=\frac{1}{J}\left(T_{e}-T_{L}-T_{d}-B \omega\right) \\
\frac{d i_{q}}{d t}=\frac{1}{L_{q}}\left[u_{q}-R_{s} i_{q}-p \omega\left(L_{d} i_{d}+\psi_{d m}\right)\right] \\
\frac{d i_{d}}{d t}=\frac{1}{L_{d}}\left[u_{d}-R_{s} i_{d}+p \omega\left(L_{q} i_{q}+\psi_{q m}\right)\right]
\end{array}\right.
$$

where $\omega$ is the angular speed; $u_{d}$ and $u_{q}$ are the stator voltages of $d$ - and $q$-axes, respectively; $i_{d}$ and $i_{q}$ are the stator currents of $d$ - and $q$-axes, respectively; $L_{d}$ and $L_{q}$ are the inductances of $d$ - and $q$-axes, respectively; and $L_{d}=L_{q}=L$ is satisfied. $R_{s}$ denotes the stator resistance, $p$ is the number of the pole pairs, $T_{e}$ is the electromagnetic torque, $T_{L}$ is the load torque, $T_{d}$ denotes the disturbing torque, $B$ is the viscous friction coefficient, $J$ is the gimbal moment of inertia, $\psi_{d m}$ and $\psi_{q m}$ are the permanent-magnet flux linkages of $d$-and $q$-axes, respectively. 
When the vector control strategy of $i_{d}=0$ is adopted, the electromagnetic torque equation can be expressed as

$$
T_{e}=1.5 p \psi_{d m} i_{q}
$$

\subsection{Periodic Disturbance Analysis}

\subsubsection{Gyro Torque Caused by Dynamic Unbalance}

The dynamic unbalance of a magnetically-levitated high-speed rotor causes undesirable synchronous unbalanced disturbance torque. As shown in Figure 2, $o-x_{g} y_{g} z_{g}$ are the frame coordinates and $o-x_{r} y_{r} z_{r}$ are the rotor coordinates. When the rotor rotates around the $o z_{r}$-axes at the angular speed of $\Omega$, the unbalanced disturbance torque can be expressed as

$$
\left\{\begin{array}{l}
\tau_{d \alpha}=m_{d} l_{d} \Omega^{2} R \cos \left(\Omega t+\varphi_{d}\right) \\
\tau_{d \beta}=m_{d} l_{d} \Omega^{2} R \sin \left(\Omega t+\varphi_{d}\right)
\end{array}\right.
$$

where $\tau_{d \alpha}$ and $\tau_{d \beta}$ denote the unbalanced disturbance torque of $x_{r}$ - and $y_{r}$-axes in the rotor coordinates, respectively; $m_{d}$ is the couple imbalance mass, $R$ is the radius of the rotor, $l_{d}$ denotes the axial distance of the two couple imbalance mass, and $\varphi_{d}$ is the initial phase of $m_{d}$.

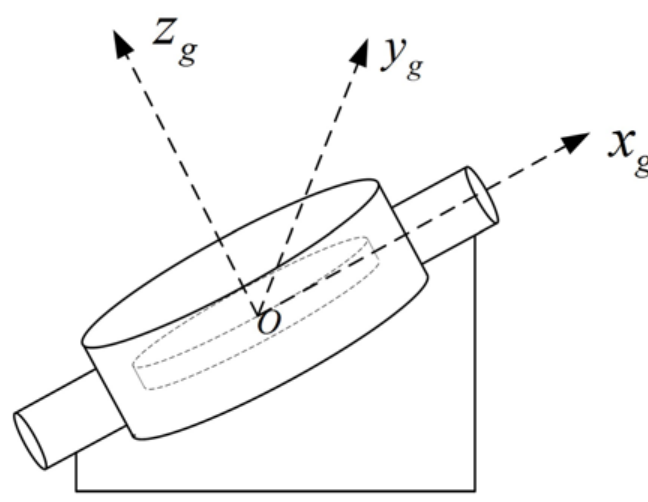

(a)

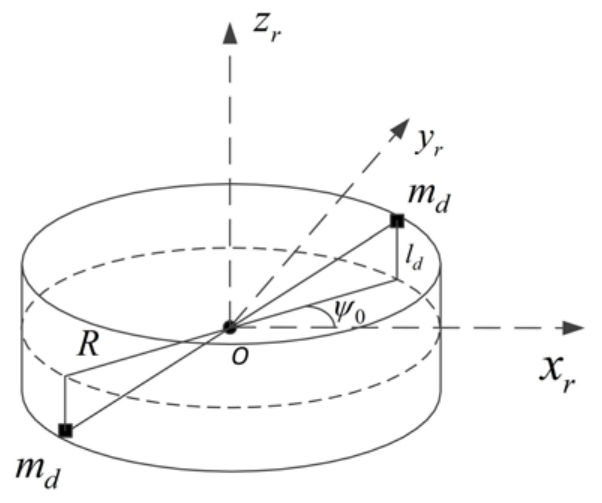

(b)

Figure 2. Coordinate definition of the SGCMG. (a) Frame coordinate definition; (b) Rotor coordinate definition.

Influenced by the unbalanced disturbance torque, the principal axis of inertia of the rotor will deviate from its geometry axis and the unbalance response that the rotor rotates round the radical direction will be activated. As a result, the gyro torque will generate a component along the $o x_{g}$-axis in the frame coordinates. This gyro torque can be obtained as

$$
T_{g x}=-J_{r} \Omega^{2} A_{r} \sin \Omega t
$$

where $J_{r}$ is the inertia of the high-speed rotor and $A_{r}$ is a coefficient related to $\tau_{d \alpha}$ and $\tau_{d \beta}$.

\subsubsection{Cogging Torque}

Cogging torque is always present in permanent magnet machines, although there is no current that excites the stator windings. It is the reluctance torque between permanent magnet poles and the 
slotted stator at no load. For radical flux PMSMs, the Fourier expression of the cogging torque can be expressed by the following Equation (5):

$$
T_{c o g}=\sum_{n=1}^{\infty} T_{n} \sin \left(n N_{c o} \omega t\right)
$$

where $T_{n}$ represents the amplitude of the $n t h$-order component, and $N_{c o}$ is the least common multiple of motor poles and slots.

\subsubsection{Flux Harmonics}

In real PMSMs, it is costly and almost impossible to achieve perfect sinusoidal flux density distribution around the air gap due to manufacturing restrictions. Thus, flux harmonics always exist. In the synchronous reference frame, the flux can be expressed by the Fourier series as

$$
\psi_{d m}=\psi_{d 0}+\sum_{n=1}^{\infty} \psi_{d 6 n} \cos (6 n p \omega t)
$$

where $\psi_{d 0}$ is the DC component and $\psi_{d 6 n}$ is the amplitude of the $6 n$th of the $d$-axes flux.

Generally, in real PMSMs, sixth and twelfth harmonics are the main part of flux harmonics. Thus, only these two components are considered. Combining Equations (2) and (6), electromagnetic torque can be rewritten as

$$
T_{e}=T_{0}+T_{6} \cos (6 p \omega t)+T_{12} \cos (12 p \omega t)
$$

where $T_{0}$ is the DC component of the electromagnetic torque, and $T_{6}$ and $T_{12}$ are the sixth-order and twelfth-order harmonic torque amplitudes.

\section{MPRC for Periodic Disturbance Suppression}

\subsection{Multiple Phase-Shift Resonant Controllers}

From the view of internal model principle (IMP), if the controller contains all the internal models that describe the reference or the disturbance signals, then the accuracy tracking or perfect disturbance rejection is ensured [26]. The internal structure of an ideal resonant controller can be shown as Figure $3 a$, letting $x(t)$ and $c(t)$ denote the input and output signal of the resonant controller, respectively. The dynamics of the resonant controller can be expressed as

$$
c(t)=\sin \left(\omega_{0} t\right) \int x(t) \sin \left(\omega_{0} t\right) d t+\cos \left(\omega_{0} t\right) \int x(t) \cos \left(\omega_{0} t\right) d t
$$

With the assumption of $\dot{\omega}_{0}=0$, by differentiating (8) twice with respect to time, we can obtain

$$
\begin{gathered}
\dot{c}(t)=\omega_{0} \cos \left(\omega_{0} t\right) \int x(t) \sin \left(\omega_{0} t\right) d t-\omega_{0} \sin \left(\omega_{0} t\right) \int x(t) \cos \left(\omega_{0} t\right) d t+x(t) \\
\ddot{c}(t)=-\omega_{0}^{2} c(t)+\dot{x}(t)
\end{gathered}
$$

The Laplace transform of (10) can be derived as

$$
G_{r}(s)=\frac{c(s)}{x(s)}=\frac{s}{s^{2}+\omega_{0}^{2}}
$$

where $\omega_{0}$ is the resonant frequency. 


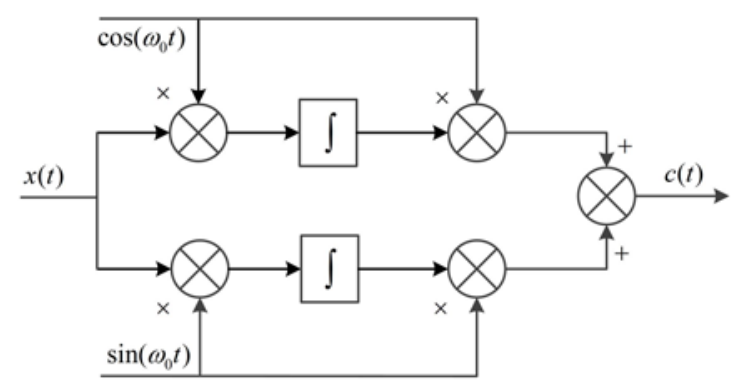

(a)

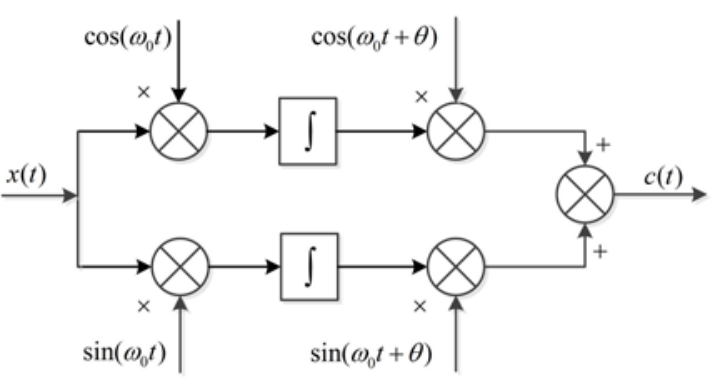

(b)

Figure 3. Block diagrams of the internal structure of resonant controllers. (a) Traditional internal structure of resonant controllers; (b) Phase-shift internal structure of resonant controllers.

The resonant controller achieves zero steady-state error for the synchronous component rejection of disturbances due to their infinite gain in the open-loop without any effect on other signals. Thus, resonant controllers are effective solutions for the periodic disturbances which were analyzed in Section 2. However, two major drawbacks exist in an ideal resonant controller. First, the abrupt phase change characteristic around its resonance frequency may affect the stability of the closed-loop system. In addition, the disturbance frequency that varies with the speed of the motor also will affect the stability margin and deteriorate the instability possibility of the closed-loop system. To maintain system stability and extend the stability margin for the entire operational speed range, an adaptive phase-shift resonant controller is adopted in this paper. The internal structure of the phase-shift resonant controller is shown in Figure $3 b$. The transfer function derivation process of the phase-shift resonant controller is the same as the ideal resonant controller. The transfer function can be expressed as

$$
G_{r}^{\prime}(s)=\frac{s \cos \theta-\omega_{0} \sin \theta}{s^{2}+\omega_{0}^{2}}
$$

where $\theta$ is the phase-shift angle.

In order to deal with multiple frequency components in periodic disturbances that are integer multiples of the motor speed, multiple resonant controllers are introduced. A multiple phase-shift controller can be expressed by the following transfer function:

$$
G_{r n}(s)=\frac{s \cos \theta-\omega_{0} \sin \theta}{s^{2}+\omega_{0}^{2}}+\frac{s \cos \theta-2 \omega_{0} \sin \theta}{s^{2}+\left(2 \omega_{0}\right)^{2}}+\cdots+\frac{s \cos \theta-n \omega_{0} \sin \theta}{s^{2}+\left(n \omega_{0}\right)^{2}}
$$

\subsection{Design and Analysis of the Current MPRC}

A resonant controller is adopted in reference [22-24] for PMSM control, but none of them discuss the tuning process. This part presents the design procedure of the $q$-axis MPRC for the current control loop, which works together with the baseline proportional-integral (PI) current control system to track $i_{\text {qref }}$ accurately and eliminate the multiply frequency harmonic currents caused by flux harmonics.

The back electromotive force (EMF) in $q$-axes, namely $p \omega \psi_{d m}$, result in current harmonics in the frequency of $6 n p \omega$, in which $6 p \omega$ and $12 p \omega$ play the major role. In order to suppress the $6 p t h$ and 12pth current harmonic components, the current control strategy of MPRC combined with PI control is designed as shown in Figure 4. Here, $G_{i q}=K_{q p}+K_{q i} / s, G_{p}(s)=K_{p w m} /\left(T_{p w m} s+1\right)$, $P_{e}(s)=1 /(L s+R)$ and $\varepsilon_{i}$ is the control gain which can determine the convergence rate. The transfer function of the current MPRC is designed as

$$
G_{r i}=\frac{s \cos \theta_{i}-6 p \omega \sin \theta_{i}}{s^{2}+(6 p \omega)^{2}}+\frac{s \cos \theta_{i}-12 p \omega \sin \theta_{i}}{s^{2}+(12 p \omega)^{2}}
$$


where $\theta_{i}$ is the phase shift of the current MPRC. Therefore, choosing back EMF disturbance $d_{e}(s)=$ $p \omega \psi_{d m}$ and current $i_{q}(s)$ as the input and output, the transfer function from $d_{e}(s)$ to $i_{q}(s)$ is derived as

$$
\frac{i_{q}(s)}{d_{e}(s)}=\frac{-P_{e}(s)}{1+P_{e}(s)\left[G_{i q}(s)+\varepsilon_{i} G_{r i}(s)\right] G_{p}(s)}
$$

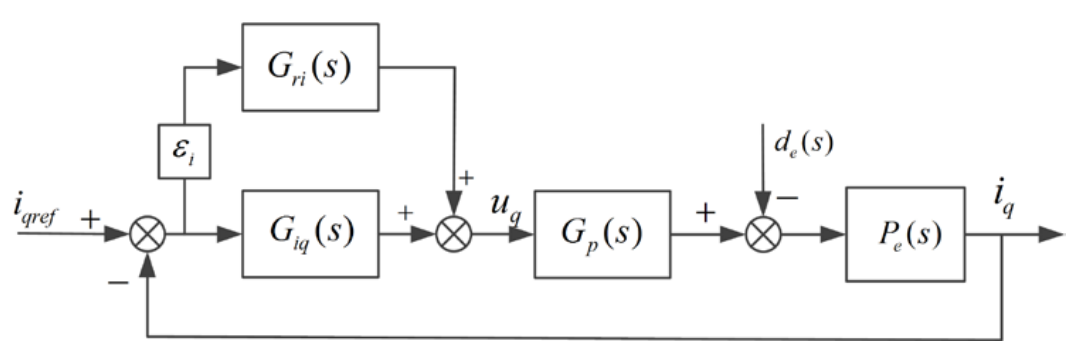

Figure 4. Schematic diagram of the proposed $q$-axes current control configuration.

According to (14) and (15), we can obtain

$$
\left\{\begin{array}{l}
\lim _{s \rightarrow j 6 p \omega} i_{q}(s)=0 \\
\lim _{s \rightarrow j 12 p \omega} i_{q}(s)=0
\end{array}\right.
$$

As can be seen from (16), the 6pth- and 12pth-order harmonic components can be theoretically suppressed. However, the DC component in the control current is not affected.

The root-locus analysis method is utilized to analyze the stability of the current control loop. Substituting (14) into (15), the transfer function from $d_{e}(s)$ to $i_{q}(s)$ can be rewritten as

$$
G_{c q}=G_{c q 0}(s) \frac{1}{1+\varepsilon_{i} G_{r i}(s) G_{c q 0}^{\prime}(s)}=G_{c q 0}(s) \frac{\left[s^{2}+(6 p \omega)^{2}\right]\left[s^{2}+(12 p \omega)^{2}\right]}{\left[s^{2}+(6 p \omega)^{2}\right]\left[s^{2}+(12 p \omega)^{2}\right]+\varepsilon_{i} M_{i q}(s) G_{c q 0}^{\prime}(s)}
$$

where $M_{i q}(s)=\left(s \cos \theta_{i}-6 p \omega \sin \theta_{i}\right)\left[s^{2}+(12 p \omega)^{2}\right]+\left(s \cos \theta_{i}-12 p \omega \sin \theta_{i}\right)\left[s^{2}+(6 p \omega)^{2}\right], G_{c q 0}(s)$ is the transfer function of the baseline system from $d_{e}(s)$ to $i_{q}(s)$, and $G_{c q 0}^{\prime}(s)$ is the transfer function of the baseline system from $u_{q}(s)$ to $i_{q}(s)$. They are expressed as follows

$$
\begin{aligned}
G_{c q 0}(s) & =\frac{-P_{e}(s)}{1+P_{e}(s) G_{i q}(s) G_{p}(s)} \\
G_{c q 0}^{\prime}(s) & =\frac{G_{p}(s) P_{e}(s)}{1+P_{e}(s) G_{i q}(s) G_{p}(s)}
\end{aligned}
$$

The original system which is composed of a baseline system with a PI controller is stable. Thus, the characteristic roots of $G_{c q 0}(s)$ are located in the left s-plane. Then, to analyze the stability of the designed current controller, we only need to investigate the characteristic root distribution of the following characteristic equation

$$
\operatorname{det}\left[\left[s^{2}+(6 p \omega)^{2}\right]\left[s^{2}+(12 p \omega)^{2}\right]+\varepsilon_{i} M_{i q}(s) G_{c q 0}^{\prime}(s)\right]=0
$$

The solution of (20), is the closed-loop root of the open-loop transfer function $\varepsilon_{i} M(s) G_{c q 0}^{\prime}(s) /\left[s^{2}+(6 p \omega)^{2}\right]\left[s^{2}+(12 p \omega)^{2}\right]$. Hence, by solving the root locus of the independent variable $\varepsilon_{i}$, the stability of the system can be determined. When $\varepsilon_{i}=0, s= \pm j 6 p \omega, \pm j 12 p \omega$. According to the characteristics of the root locus, the root locus originates from the poles of the open-loop transfer function. Only when the angle of emergence is within the range $\left(\frac{\pi}{2}, \frac{3 \pi}{2}\right)$, the roots 
are all located in the left half-plane, that is, the system is stable. Therefore, in order to keep the stability of the system, the following condition must be satisfied:

$$
\arg \left[\left.\frac{\partial s}{\partial \varepsilon_{i}}\right|_{\varepsilon_{i}=0}\right] \in\left(\frac{\pi}{2}, \frac{3 \pi}{2}\right)
$$

When the gimbal servo motor is operating at speed $\omega$, we can obtain the following expression

$$
\left.\frac{\partial s}{\partial \varepsilon_{i}}\right|_{\varepsilon_{i}=0, s=j 6 p \omega}=-\frac{\left(\cos \theta_{i}+j \sin \theta_{i}\right)}{2} G_{c q 0}^{\prime}(j 6 p \omega)
$$

According to (21) and (22), to make the system stable, the condition must be met as follows:

$$
-\frac{\pi}{2}<\arg \left[G_{c q 0}^{\prime}(j 6 p \omega)\right]+\theta_{i}<\frac{\pi}{2}
$$

\subsection{Design and Analysis of the Speed MPRC}

In the design procedure of the speed MPRC, the current loop is taken as a first-order system. As analyzed in the previous section, there are three disturbances in the speed loop: the cogging torque, the flux harmonics torque and the gyro torque caused by the dynamic torque. According to the parameters of the gimbal servo PMSM shown in Table 1, the harmonic frequencies contained in the cogging torque are $60 n \omega$, those in the flux harmonics torque are $60 n \omega$ and those in the gyro torque are $\Omega$. Considering the fact that the higher order harmonics have little effect on speed ripples, only the frequencies in $60 \omega$ and $\Omega$ are picked up by making a compromise between complexity and performance. Thus, the speed MPRC parallel with a PI speed controller is designed, as per the structure shown in Figure 5.

Table 1. Parameters of the gimbal servo PMSM.

\begin{tabular}{ccc}
\hline Parameters & Values & Unit \\
\hline Rated speed & 150 & $\mathrm{rpm}$ \\
Pole pairs & 10 & - \\
Slot & 60 & - \\
Torque constant & 1.1 & $\mathrm{Nm} / \mathrm{A}$ \\
Stator resistance & 7.4 & $\Omega$ \\
$\quad \begin{array}{c}\text { axes } \\
\text { inductance }\end{array}$ & 6 & $\mathrm{mH}$ \\
$\quad$ axes & 6 & $\mathrm{mH}$ \\
inductance & & $\mathrm{kg} \cdot \mathrm{m}^{2}$ \\
\hline Inertia & 0.024 & \\
\hline
\end{tabular}

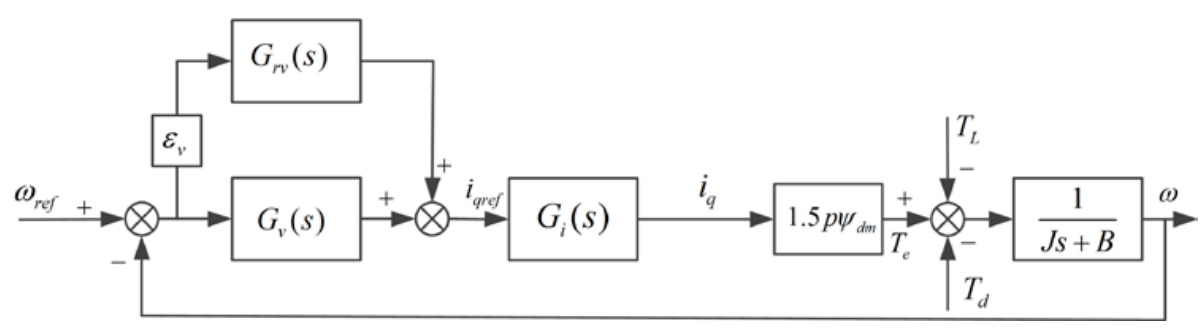

Figure 5. Schematic diagram of the proposed speed controller configuration.

The transfer function of the speed MPRC is designed as

$$
G_{r v}(s)=\frac{s \cos \theta_{v}-6 p \omega \sin \theta_{v}}{s^{2}+(6 p \omega)^{2}}+\varepsilon_{\Omega} \frac{s \cos \theta_{\Omega}-\Omega \sin \theta_{\Omega}}{s^{2}+\Omega^{2}}
$$


where $\theta_{v}$ and $\theta_{\Omega}$ are the phase-shift angles of speed MPRC. Choosing torque disturbance $T_{d}(s)=$ $T_{6} \cos (60 \omega t)+T_{g x}$ and speed $\omega(s)$ as input and output, respectively, the transfer function from $T_{d}(s)$ to $\omega(s)$ is derived as

$$
\frac{\omega(s)}{T_{d}(s)}=\frac{-P_{m}(s)}{1+K_{T} P_{m}(s)\left[G_{v}(s)+\varepsilon_{v} G_{r v}(s)\right] G_{i}(s)}
$$

where $P_{m}(s)=1 /(J s+B), K_{T}=1.5 p \psi_{d 0}, G_{v}(s)=K_{v p}+K_{v i} / s, G_{i}(s)$ is the first-order system of current loop, $\varepsilon_{v}$ and $\varepsilon_{\Omega}$ are the control gain.

According to (24) and (25), we can obtain

$$
\left\{\begin{array}{c}
\lim _{s \rightarrow j 6 p \omega} \omega(s)=0 \\
\lim _{s \rightarrow j \Omega} \omega(s)=0
\end{array}\right.
$$

Similarly, substituting (24) into (25), the transfer function of (25) can be rewritten as

$$
G_{c v}=G_{c v 0}(s) \frac{1}{1+\varepsilon_{v} G_{r v}(s) G_{c v 0}^{\prime}(s)}=G_{c v 0}(s) \frac{\left[s^{2}+(6 p \omega)^{2}\right]\left[s^{2}+\Omega^{2}\right]}{\left[s^{2}+(6 p \omega)^{2}\right]\left[s^{2}+\Omega^{2}\right]+\varepsilon_{v} M_{v}(s) G_{c v 0}^{\prime}(s)}
$$

where $M_{v}(s)=\left(s \cos \theta_{v}-6 p \omega \sin \theta_{v}\right)\left(s^{2}+\Omega^{2}\right)+\left(s \cos \theta_{\Omega}-\Omega \sin \theta_{\Omega}\right)\left[s^{2}+(6 p \omega)^{2}\right], G_{c v 0}(s)$ and $G_{c v 0}^{\prime}(s)$ are the transfer function of the baseline system from $T_{d}(s)$ to $\omega(s)$ and the transfer function of the baseline system from $i_{\text {qref }}(s)$ to $\omega(s)$, respectively. They can be expressed as follows

$$
\begin{aligned}
G_{c v 0}(s) & =\frac{-P_{m}(s)}{1+K_{T} P_{m}(s) G_{i}(s) G_{v}(s)} \\
G_{c v 0}^{\prime}(s) & =\frac{G_{i}(s) P_{m}(s)}{1+K_{T} P_{m}(s) G_{i}(s) G_{v}(s)}
\end{aligned}
$$

Similarly, in order to analyze the stability of the designed speed controller, we only need to investigate the characteristic root distribution of the following characteristic equation

$$
\operatorname{det}\left[\left[s^{2}+(6 p \omega)^{2}\right]\left(s^{2}+\Omega^{2}\right)+\varepsilon_{v} M_{v}(s) G_{c v 0}^{\prime}(s)\right]=0
$$

The solutions of (30), namely, the closed-loop roots of the open-loop transfer function $\varepsilon_{v} M_{v}(s) G_{c v 0}^{\prime}(s) /\left[s^{2}+(6 p \omega)^{2}\right]\left(s^{2}+\Omega^{2}\right)$. Hence, by solving the root locus of the independent variable $\varepsilon_{v}$, the stability of the system can be determined. $s= \pm j 6 p \omega, \pm j \Omega$ can be obtained when $\varepsilon_{v}=0$. According to the characteristics of the root locus, the root locus originates from the poles of the open-loop transfer function. Only when the angle of emergence is within the range $\left(\frac{\pi}{2}, \frac{3 \pi}{2}\right)$, the roots are all located in the left half-plane, namely, the system is stable. Therefore, in order to keep the stability of the system, the following condition must be satisfied:

$$
\arg \left[\left.\frac{\partial s}{\partial \varepsilon_{v}}\right|_{\varepsilon_{v}=0}\right] \in\left(\frac{\pi}{2}, \frac{3 \pi}{2}\right)
$$

When the gimbal servo motor and high-speed motor are operating at speed $\omega$ and $\Omega$, respectively, we can obtain the following expression

$$
\left\{\begin{array}{c}
\left.\frac{\partial s}{\partial \varepsilon_{v}}\right|_{\varepsilon_{v}=0, s=j 6 p \omega}=-\frac{\left(\cos \theta_{v}+j \sin \theta_{v}\right)}{2} G_{c v 0}^{\prime}(j 6 p \omega) \\
\left.\frac{\partial s}{\partial \varepsilon_{\Omega}}\right|_{\varepsilon_{\Omega}=0, s=j \Omega}=-\frac{\left(\cos \theta_{\Omega}+j \sin \theta_{\Omega}\right)}{2} G_{c v 0}^{\prime}(j \Omega)
\end{array}\right.
$$


According to (31) and (32), to make the system stable, the condition must be met as follows:

$$
\left\{\begin{array}{c}
-\frac{\pi}{2}<\arg \left[G_{c v 0}^{\prime}(j 6 p \omega)\right]+\theta_{v}<\frac{\pi}{2} \\
-\frac{\pi}{2}<\arg \left[G_{c v 0}^{\prime}(j \Omega)\right]+\theta_{\Omega}<\frac{\pi}{2}
\end{array}\right.
$$

\section{Simulation and Experimental Verification}

\subsection{Simulation and Experimental Setup}

Figure 6 illustrates the configuration of the MSCMG control system for experiments. Figure 7 shows the overall block diagram of the proposed MPRC-based control strategy for a gimbal servo system in MSCMG. The servo motor of the gimbal system is a PMSM with a sinusoidal back EMF. The rotor position is measured and decoded to 20-bit data based on the twin-channel resolvers which has the characteristics of high accuracy and high reliability. The phase currents are measured by the high-bandwidth hall-effect current sensor and fed to the controller through a 16-bit analog to digital converter. The experimental setup based on a floating-point TMS320C6713 digital signal processor (DSP) and a Xilinx XCS400 field-programmable gate array (FPGA) is implemented. The high-speed DSP with sampling frequencies kept at $20 \mathrm{kHz}$ and $1 \mathrm{kHz}$ for current-loop and speed-loop performs all the digital control algorithms. The FPGA is used to implement analog to digital interface, generate driving signal and realize signal detection. All the parameters of the gimbal servo system used in the simulation and experiments are listed in Tables 1 and 2.

Table 2. Parameters of control system.

\begin{tabular}{cccccc}
\hline Parameters & Values & Unit & Parameters & Values & Unit \\
\hline$K_{q p}$ & 38 & v $/ \mathrm{A}$ & $K_{v p}$ & 13 & $\mathrm{~A} \cdot \mathrm{s} / \mathrm{rad}$ \\
$K_{q i}$ & 42,000 & v $/ \mathrm{A}$ & $K_{v i}$ & 8900 & $\mathrm{~A} \cdot \mathrm{s} / \mathrm{rad}$ \\
$T_{p w m}$ & 0.00005 & $\mathrm{~s}$ & $\varepsilon_{v}$ & 8000 & - \\
$\varepsilon_{i}$ & 10,000 & - & $\varepsilon_{\Omega}$ & 0.6 & - \\
\hline
\end{tabular}

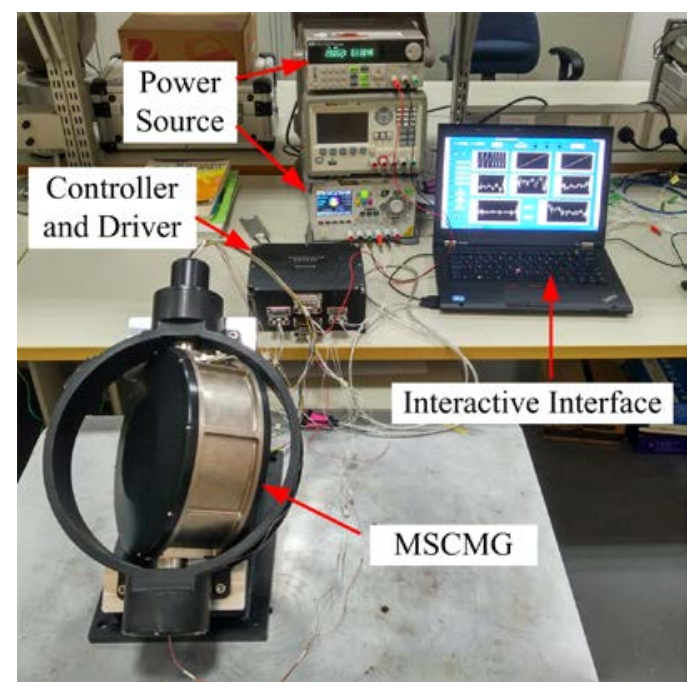

Figure 6. Photograph of the prototype. 


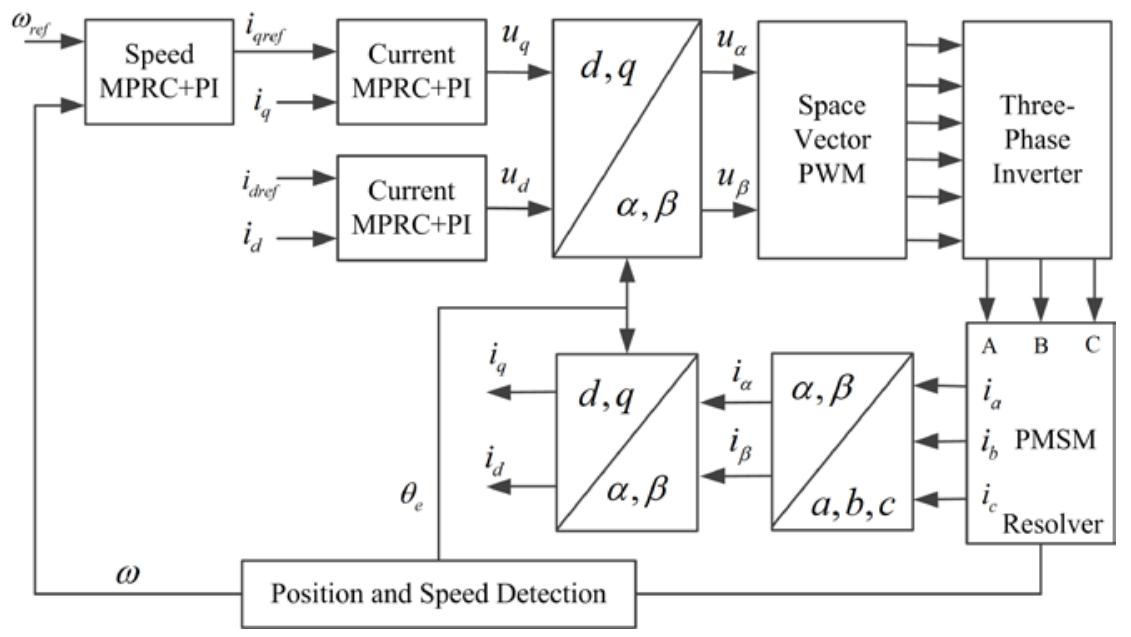

Figure 7. Block diagram of the proposed MPRC-based control strategy for PMSM.

To verify the performance of the proposed MPRC+PI control scheme, the simulation and experiment were carried out under the following four cases.

(Case 1) The gimbal servo motor speed keeps constant at $1 \mathrm{rad} / \mathrm{s}$ under speed PI control and the suspended high-speed rotor keeps at a standstill to verify the harmonic current suppression performance.

(Case 2) The gimbal servo motor speed keeps constant at $1 \mathrm{rad} / \mathrm{s}$ under the proposed MPRC+PI control and the speed of the suspended high-speed rotor operates at 10,000 rpm and $6000 \mathrm{rpm}$.

(Case 3) The gimbal servo motor speed keeps constant at $0.01 \mathrm{rad} / \mathrm{s}$ under the proposed MPRC+PI control and the speed of the suspended high-speed rotor operates at 10,000 rpm and $6000 \mathrm{rpm}$.

(Case 4) The gimbal servo motor speed varies with a frequency of $3 \mathrm{HZ}$ and amplitude of $1 \mathrm{rad} / \mathrm{s}$, and the suspended high-speed rotor keeps constant at 10,000 rpm.

\subsection{Simulation Results}

The magnitude-frequency and phase-frequency characteristic diagrams of (19) and (29) are shown in Figure 8. As can be seen from the diagrams, both the current and speed system have a strong inhibition on disturbances at low frequency. Besides, the magnitude of the interference associated with the gimbal torque motor speed is small when the motor operates at ultra-low speed. Therefore, when the operating speed of the gimbal torque motor is lower than $0.1 \mathrm{rad} / \mathrm{s}$, the phase-shift resonant controller for gyro torque rejection is activated only. According to the phase ranges shown in Figure 8 at different operating speeds, the compensation phases are given in (34)-(36) to maintain the stability of the system.

$$
\begin{gathered}
\theta_{i}= \begin{cases}-\frac{\pi}{2} & (0.1 \leq \omega<6.5 \mathrm{rad} / \mathrm{s}) \\
0 & (\omega \geq 6.5 \mathrm{rad} / \mathrm{s})\end{cases} \\
\theta_{v}= \begin{cases}-\frac{\pi}{2} & (0.1<\omega<6.3 \mathrm{rad} / \mathrm{s}) \\
0 & (\omega \geq 6.3 \mathrm{rad} / \mathrm{s})\end{cases} \\
\theta_{\Omega}=\left\{\begin{array}{cc}
-\frac{\pi}{2} & (0<\Omega \leq 382 \mathrm{rad} / \mathrm{s}) \\
0 & (382<\Omega \leq 910 \mathrm{rad} / \mathrm{s}) \\
\frac{\pi}{2}(\Omega>910 \mathrm{rad} / \mathrm{s})
\end{array}\right.
\end{gathered}
$$




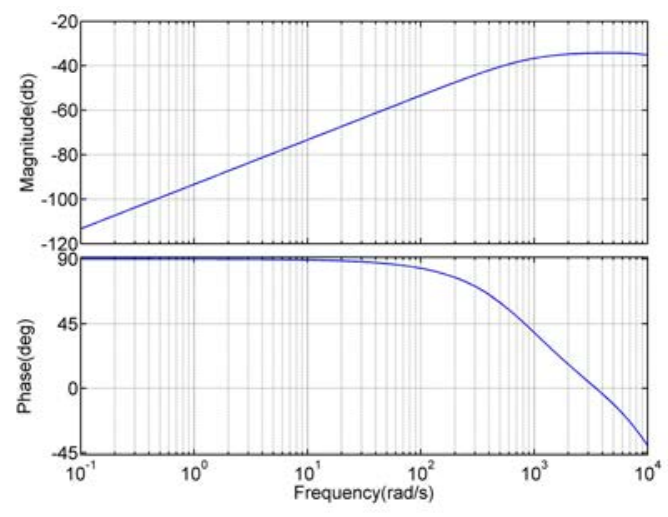

(a)

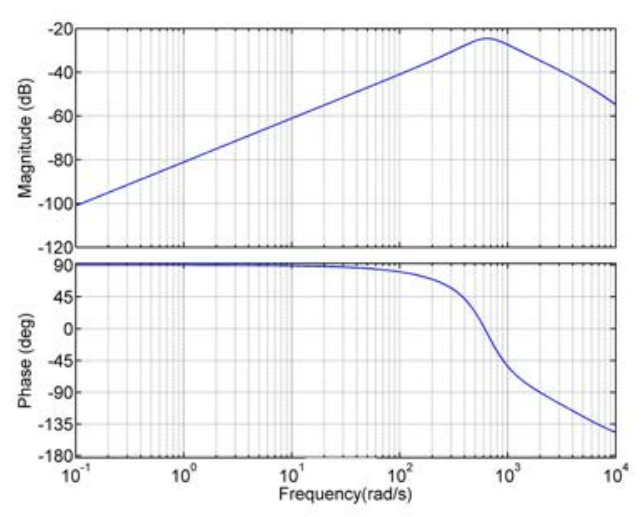

(b)

Figure 8. Bode diagrams of the control system. (a) Current loop bode diagram; (b) Speed loop bode diagram.

\subsubsection{Simulation 1-Harmonic Current Suppression}

This simulation is conducted under case (1). In this simulation, the traditional PI controller is adopted in the speed loop and the speed reference of the servo motor is $1 \mathrm{rad} / \mathrm{s}$. Figure $9 \mathrm{a}, \mathrm{b}$ provide the performance of the PI current controller and multiple phase-shift resonant current controller, respectively. It can be seen from Figure 9 a that there are tracking errors between $i_{q}$ and $i_{\text {qref }}$, and there are periodic ripples with a frequency of $60 \mathrm{rad} / \mathrm{s}$ and a peak-to-peak value of about $0.01 \mathrm{~A}$ in $i_{d}$ under current PI control. By contrast, as depicted in Figure $9 \mathrm{~b}$, the $i_{q}$ and $i_{\text {qref }}$ curves are almost coincident and the current ripples in $i_{d}$ are suppressed completely. In addition, the speed of the servo motor oscillates with a peak-to-peak value about $0.014 \mathrm{rad} / \mathrm{s}$ and $0.012 \mathrm{rad} / \mathrm{s}$ under the current PI control and the current MPRC+PI control schemes, respectively. The harmonic current has little effect on velocity performance. Simulation results verify that the proposed zero harmonic current control method can suppress the harmonic currents effectively.

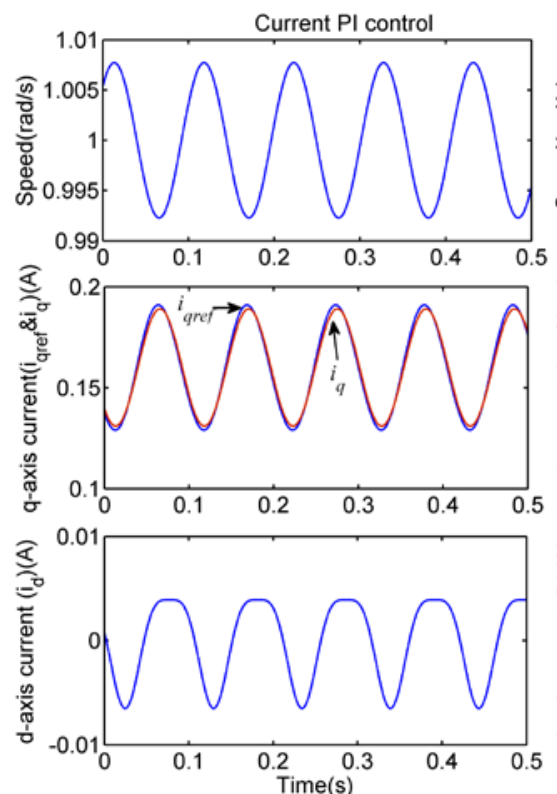

(a)
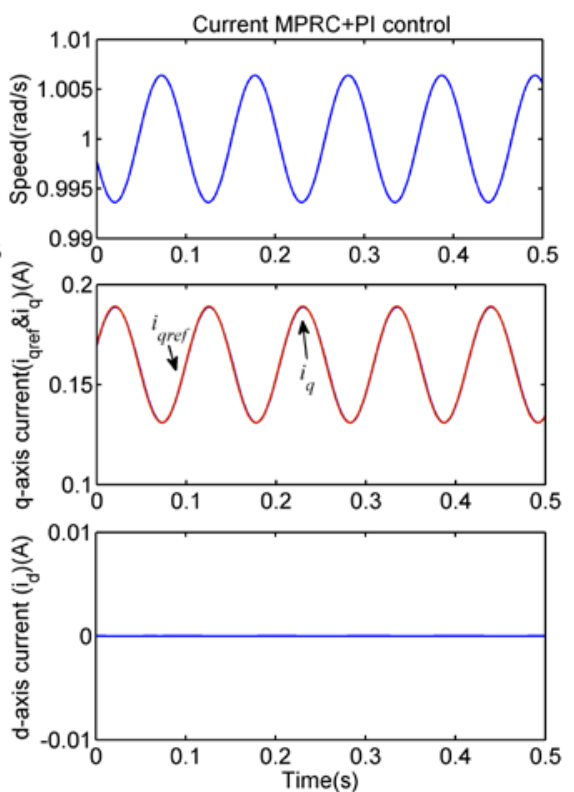

(b)

Figure 9. Simulation waveforms of $d$-axes, $q$-axes currents and speed under case (1). (a) Waveforms under current PI control; (b) Waveforms under current MPRC+PI control. 


\subsubsection{Simulation 2-Speed Ripple Suppression}

This simulation is conducted under case (2), case (3) and case (4) to investigate the periodic disturbance rejection performance in the speed loop. In this simulation, MPRC+PI control is applied in the speed control loop. The speed references of $1 \mathrm{rad} / \mathrm{s}$ and $0.01 \mathrm{rad} / \mathrm{s}$ are firstly given to evaluate the performance in the steady-state. Generally speaking, the bandwidth of the speed command that is given by the attitude control computer is less than $3 \mathrm{HZ}$. Thus, the sinusoidal speed reference with a frequency of $3 \mathrm{HZ}$ and an amplitude of $1 \mathrm{rad} / \mathrm{s}$ is applied to evaluate the performance of the proposed MPRC+PI control in the dynamic process.

The simulation results under case (2), case (3) and case (4) are shown in Figures 10-12, respectively. In Figures 10 and 11, the MPRC is activated at the moment of $0.25 \mathrm{~s}$. In Figure 12, the MPRC is activated at the moment of $0.5 \mathrm{~s}$. It can be seen that the speed oscillates obviously under PI control. The amplitude of the speed harmonics caused by the dynamic unbalance of the high-speed rotor does not vary with the changing speed of the gimbal servo PMSM, and its peak-to-peak value is $0.018 \mathrm{rad} / \mathrm{s}$ and $0.01 \mathrm{rad} / \mathrm{s}$, with the high-speed rotor operating at 10,000 rpm and $6000 \mathrm{rpm}$, respectively. The 60th speed harmonic amplitude varies with the operational speed of the PMSM. Its peak-to-peak value is about $0.014 \mathrm{rad} / \mathrm{s}$ at an operating speed of $1 \mathrm{rad} / \mathrm{s}$ and is about $0.0002 \mathrm{rad} / \mathrm{s}$ at a speed of $0.01 \mathrm{rad} / \mathrm{s}$. Thus, it can be seen from Figure 10 that when the gimbal servo motor speed keeps constant at $1 \mathrm{rad} / \mathrm{s}$, the speed oscillating ranges are 0.984 to $1.016 \mathrm{rad} / \mathrm{s}$ and 0.988 to $1.012 \mathrm{rad} / \mathrm{s}$, with the high-speed rotor operating at 10,000 rpm and $6000 \mathrm{rpm}$, respectively. As depicted in Figure 11, when the gimbal servo motor speed keeps constant at $0.01 \mathrm{rad} / \mathrm{s}$, the speed oscillating ranges are $0.0089-0.0191 \mathrm{rad} / \mathrm{s}$ and $0.0049-0.0051 \mathrm{rad} / \mathrm{s}$, with the high-speed rotor operating at 10,000 rpm and $6000 \mathrm{rpm}$, respectively. By contrast, in the MPRC+PI control, the amplitudes of those two kinds of speed harmonics are almost reduced to zero. Figure 12 shows that the proposed method has an excellent dynamic performance during the whole operating speed range.
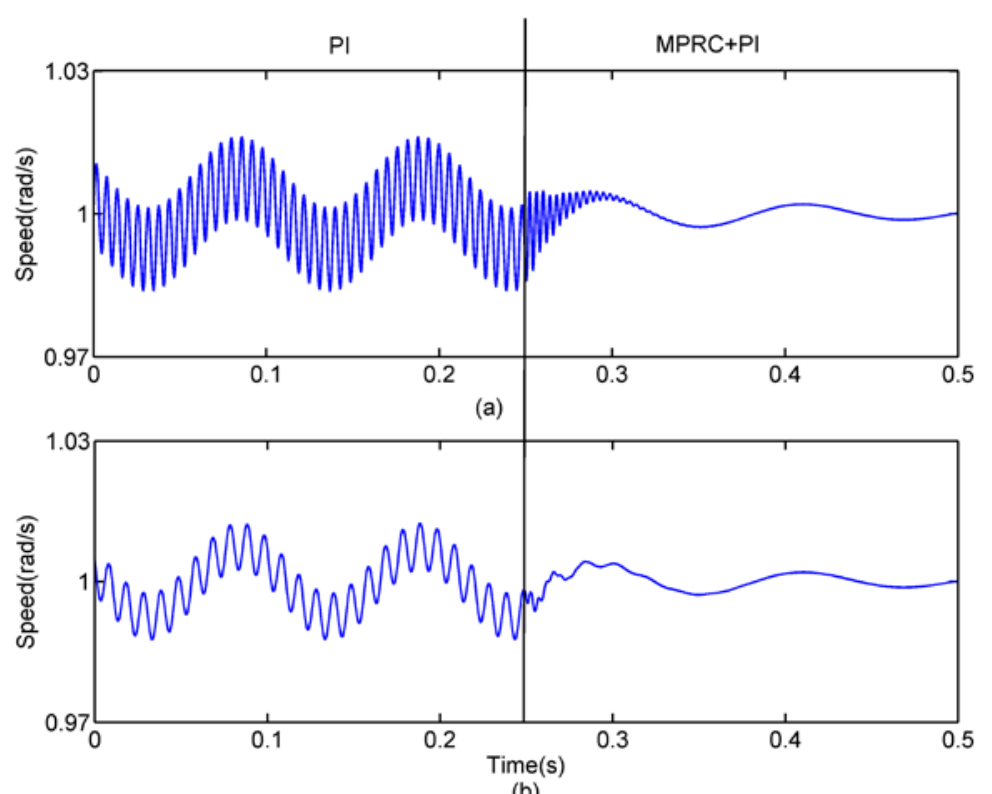

(b)

Figure 10. Simulation results under case (2). (a) Speed response with high-speed rotor operating at $10,000 \mathrm{rpm}$; (b) Speed response with high-speed rotor operating at $6000 \mathrm{rpm}$. 

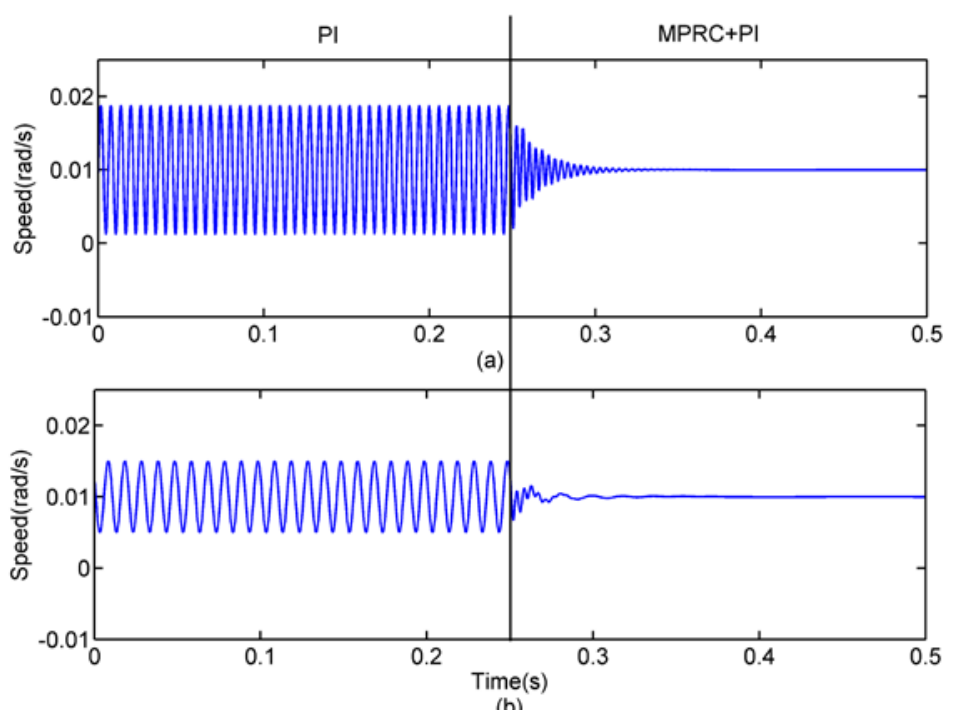

(b)

Figure 11. Simulation results under case (3). (a) Speed response with high-speed rotor operating at $10,000 \mathrm{rpm}$; (b) Speed response with high-speed rotor operating at $6000 \mathrm{rpm}$.
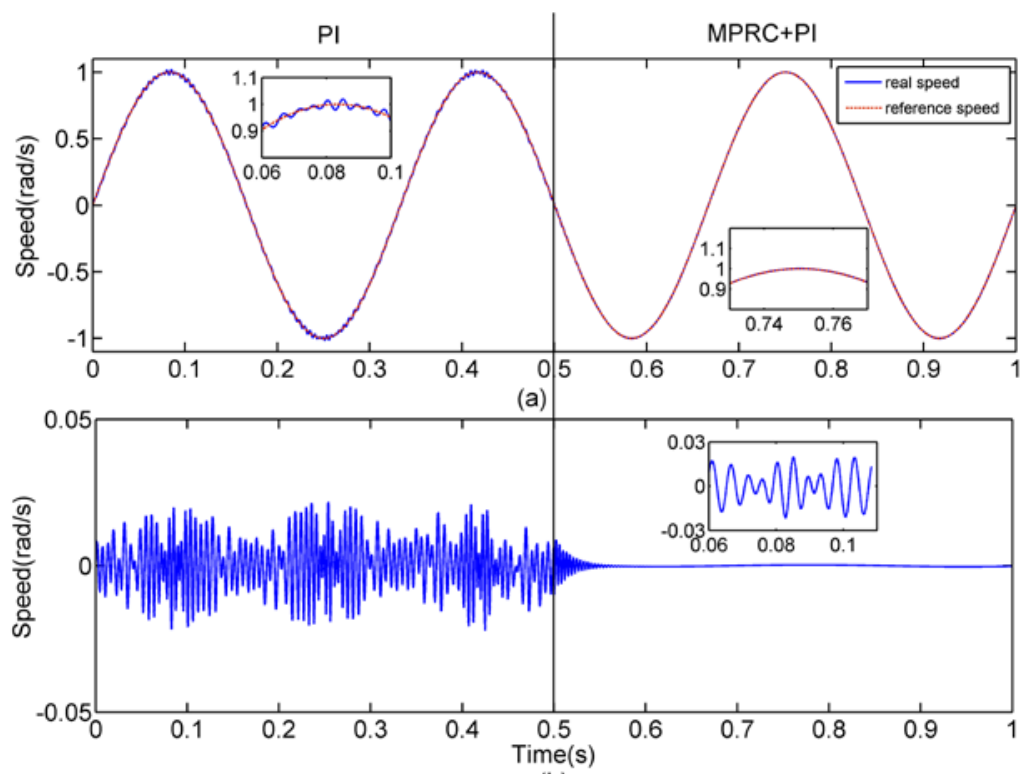

(b)

Figure 12. Simulation results under case (4). (a) Waveform of sinusoidal reference and speed response; (b) Waveform of speed error under sinusoidal reference.

\subsection{Experiment Results}

Figure 13 provides the comparison experimental results of current MPRC+PI control in case (1). It can be seen from Figure 13a that there are tracking errors between $i_{q}$ and $i_{q r e f}$, and there are periodic ripples with a frequency of $60 \mathrm{rad} / \mathrm{s}$ and a peak-to-peak value of about $0.02 \mathrm{~A}$ in $i_{d}$ under current PI control. By contrast, as depicted in Figure 13b, the $i_{q}$ and $i_{\text {qref }}$ curves are almost coincident and the current ripples in $i_{d}$ are suppressed completely. The gimbal servo motor speed oscillates with a range of $0.986 \mathrm{rad} / \mathrm{s}$ to $1.012 \mathrm{rad} / \mathrm{s}$ in speed PI control and is influenced little by the current harmonics. The experimental results demonstrate that the proposed control scheme achieves satisfactory speed ripple suppression performance. 

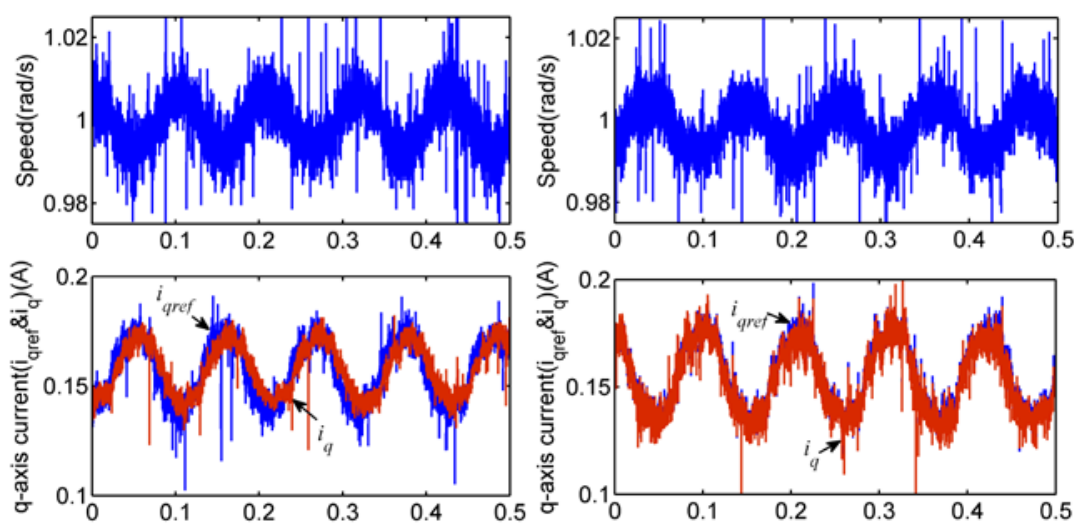

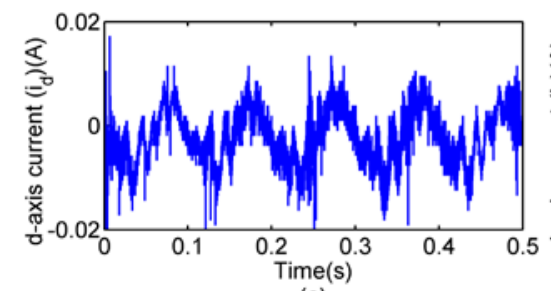

(a)

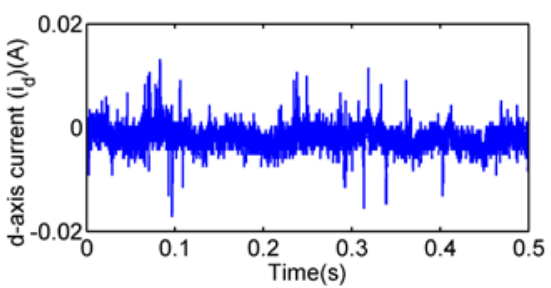

(b)

Figure 13. Experimental waveforms of $d$-axis, $q$-axis currents and speed under case (1). (a) Waveforms under current PI control; (b) Waveforms under current MPRC+PI control.

The experimental results of the speed response under case (2) and case (3) are shown in Figures 14 and 15, respectively. In Figure 14, the speed of the gimbal servo motor oscillates seriously under PI control and the fluctuation ranges are 0.974 to $1.025 \mathrm{rad} / \mathrm{s}$ and 0.985 to $1.016 \mathrm{rad} / \mathrm{s}$, corresponding with the high-speed rotor operating at 10,000 rpm and $6000 \mathrm{rpm}$, respectively, whereas the speed steady-state error is controlled to be within $\pm 0.004 \mathrm{rad} / \mathrm{s}$ under the proposed MPRC $+\mathrm{PI}$ control method. In Figure 15, the gimbal servo motor speed is constant at $0.01 \mathrm{rad} / \mathrm{s}$, the speed harmonic amplitudes are $0.005 \mathrm{rad} / \mathrm{s}$ and $0.0095 \mathrm{rad} / \mathrm{s}$, corresponding to the high-speed rotor operating at the speed of $6000 \mathrm{rpm}$ and 10,000 rpm, respectively. By contrast, the speed steady-state error of the gimbal servo system is maintained at $\pm 0.003 \mathrm{rad} / \mathrm{s}$ under the proposed MPRC+PI control. The detailed experiment results of the speed ripple harmonics in case (2) and case (3) are depicted in Tables 3 and 4, respectively. According to the above experimental results, the effectiveness of MPRC+PI control is clearly revealed under various steady-state operating speeds.

Figure 16 shows the experimental results under case (4), in which the sinusoidal speed reference with a frequency of $3 \mathrm{~Hz}$ and amplitude of $1 \mathrm{rad} / \mathrm{s}$ is given. According to Figure 16a,c, the actual speed of the servo motor cannot track the reference very well, with a maximal speed error reaching $0.036 \mathrm{rad} / \mathrm{s}$. The speed harmonic in $1047 \mathrm{rad} / \mathrm{s}$ is the main factor of speed error. Compared to Figure 16a,c, the actual output speed in Figure 16b,d can follow the reference better, with a maximal speed error of only about $0.007 \mathrm{rad} / \mathrm{s}$, and the main influence factor is nonlinear friction. The effectiveness and excellent dynamic performance of the proposed MPRC+PI control is clearly confirmed. 

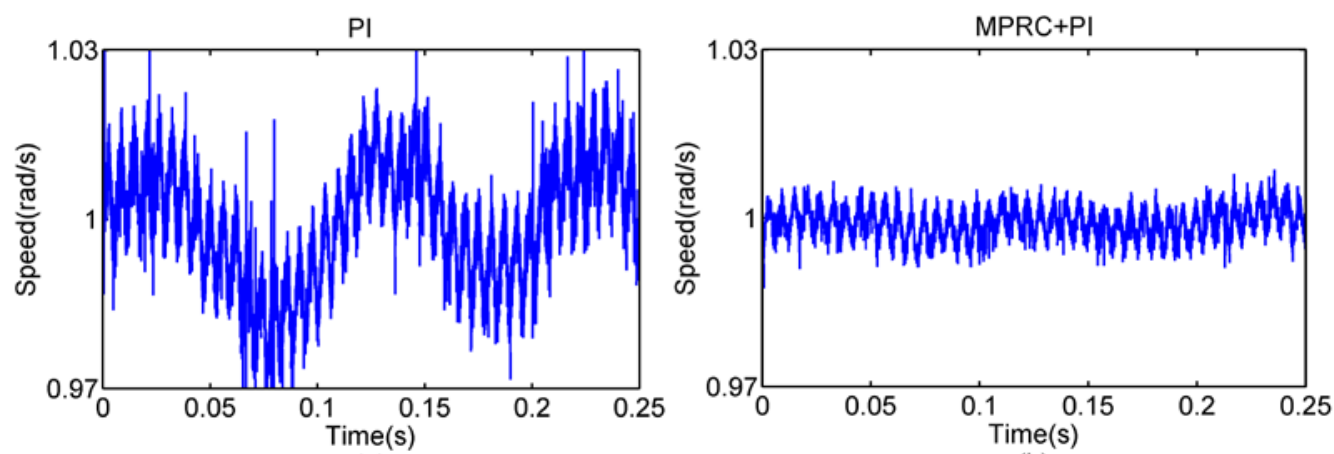

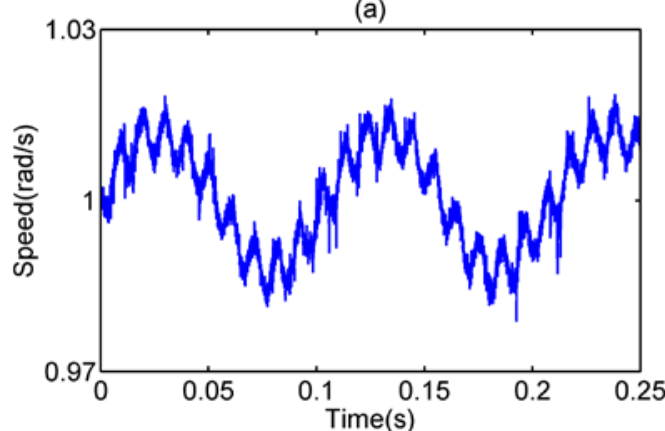

(c)

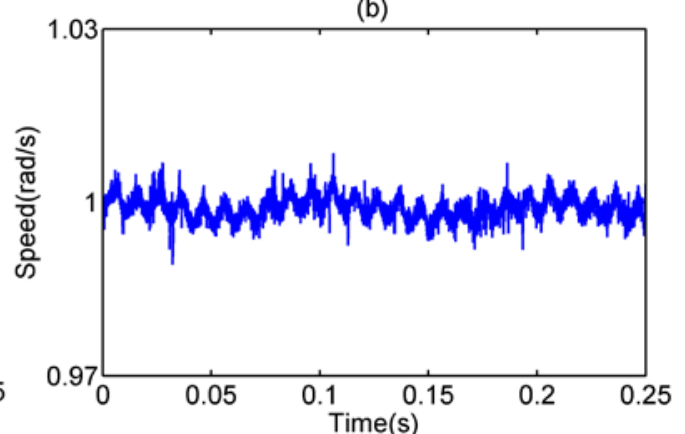

(d)

Figure 14. Experimental results under case (2). (a) Speed response under PI control with high-speed rotor operating at 10,000 rpm; (b) Speed response under MPRC+PI control with high-speed rotor operating at 10,000 rpm; (c) Speed response under PI control with high-speed rotor operating at $6000 \mathrm{rpm}$; (d) Speed response under MPRC+PI control with high-speed rotor operating at $6000 \mathrm{rpm}$.

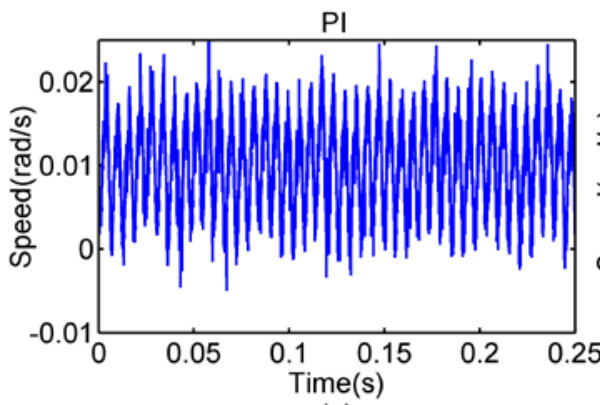

(a)

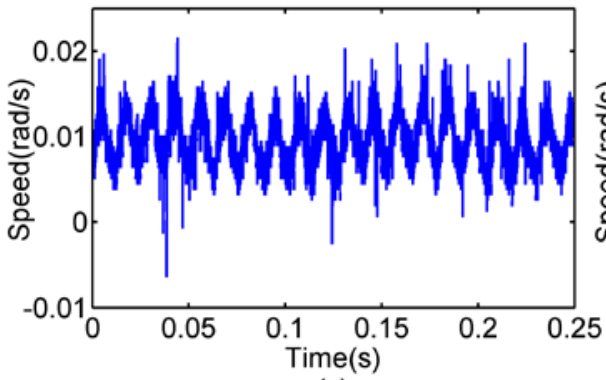

(c)

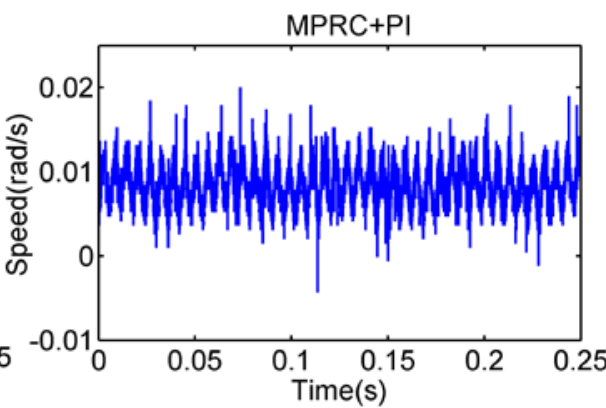

(b)

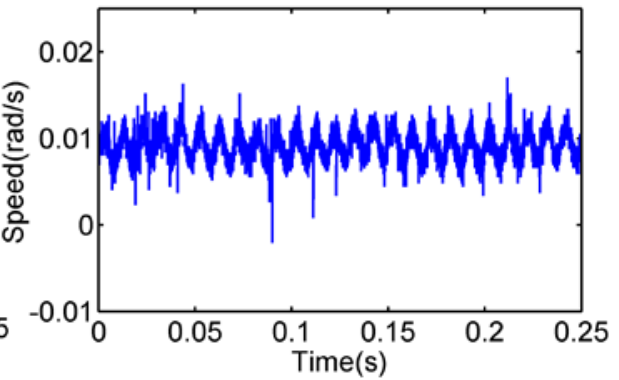

(d)

Figure 15. Experimental results under case (3). (a) Speed response under PI control with high-speed rotor operating at 10,000 rpm; (b) Speed response under MPRC+PI control with high-speed rotor operating at 10,000 rpm; (c) Speed response under PI control with high-speed rotor operating at $6000 \mathrm{rpm}$; (d) Speed response under MPRC+PI control with high-speed rotor operating at $6000 \mathrm{rpm}$. 
Table 3. Details of the harmonics in speed under case (2).

\begin{tabular}{|c|c|c|c|c|}
\hline \multirow{2}{*}{ Control Method } & \multirow{2}{*}{ Speed of High-Speed Rotor (rpm) } & \multicolumn{3}{|c|}{ Amplitude of Hrmonics in Speed } \\
\hline & & $60 \mathrm{rad} / \mathrm{s}$ & $628 \mathrm{rad} / \mathrm{s}$ & $1047 \mathrm{rad} / \mathrm{s}$ \\
\hline PI & 6000 & 0.013 & 0.005 & - \\
\hline $\mathrm{MPRC}+\mathrm{PI}$ & 6000 & 0.002 & 0.0012 & - \\
\hline PI & 10,000 & 0.013 & - & 0.0095 \\
\hline $\mathrm{MPRC}+\mathrm{PI}$ & 10,000 & 0.002 & - & 0.002 \\
\hline
\end{tabular}

Table 4. Details of the harmonics in speed under case (3).

\begin{tabular}{ccccc}
\hline \multirow{2}{*}{ Control Method } & \multirow{2}{*}{ Speed of High-Speed Rotor (rpm) } & \multicolumn{3}{c}{ Amplitude of Harmonics in Speed } \\
\cline { 3 - 5 } & & $\mathbf{0 . 6} \mathbf{~ r a d} / \mathbf{s}$ & $\mathbf{6 2 8} \mathbf{~ r a d} / \mathbf{s}$ & $\mathbf{1 0 4 7} \mathbf{~ r a d} / \mathbf{s}$ \\
\hline PI & 6000 & 0.0001 & 0.005 & - \\
MPRC+PI & 6000 & 0.0001 & 0.0013 & - \\
PI & 10,000 & 0.0001 & - & 0.0095 \\
MPRC+PI & 10,000 & 0.0001 & - & 0.002 \\
\hline
\end{tabular}

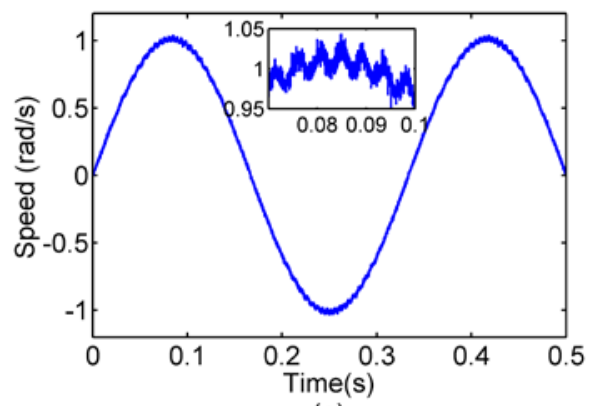

(a)

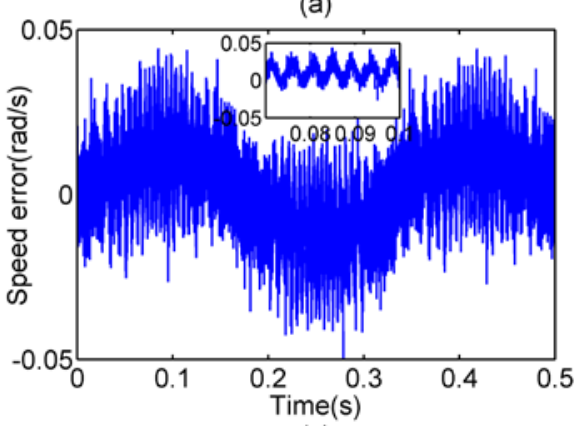

(c)

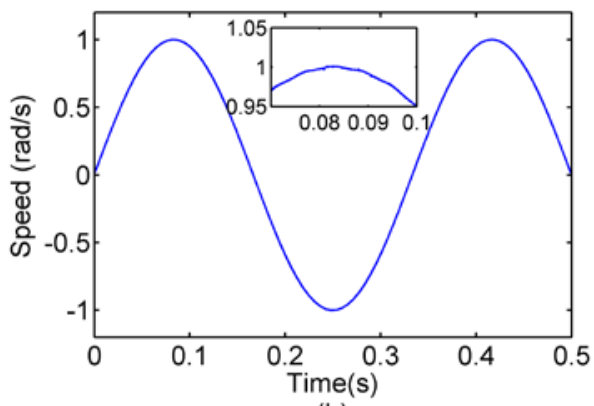

(b)

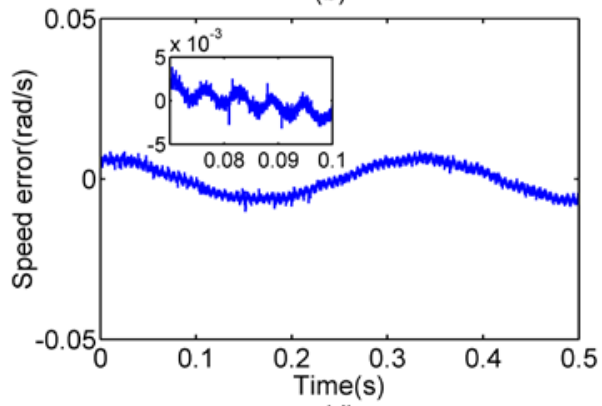

(d)

Figure 16. Experimental results under case (4). (a) Speed response under PI control; (b) Speed response under MPRC+PI control; (c) Speed error under PI control; (d) Speed error under MPRC+PI control.

\section{Conclusions}

Periodic torque ripples are important factors affecting the high-precision speed tracking control of a gimbal servo system in MSCMG. Periodic torque ripples caused by the cogging torque, flux harmonic and mass unbalance of the high-speed rotor were analyzed. To effectively minimize the torque ripples, a method that plugs multiple phase-shift resonant controllers into the baseline speed and current control is proposed. Different phases were chosen as compensation to ensure the stability of the closed-loop system at variable speed rotations of both the gimbal servo motor and the high-speed motor. The method presented is easy to realize and is propitious to engineering applications. The effectiveness of the proposed method was verified by both the simulation and the experimental results. 
Acknowledgments: This research was supported in part by the National Natural Science Foundation of China (Grant No. 61503395), in part by the National Natural Science Foundation of China (Grant No. 61603405), and in part by the Hunan Provincial Natural Science Foundation of China under Grant No. 2016JJ4007.

Author Contributions: Jian Feng conceived, designed and wrote this paper. Jian Feng and Qing Wang designed and conducted the experiments. Jian Feng and Kun Liu set up the experiments. All authors contributed to analyzing the experimental data. All authors read and approved this paper.

Conflicts of Interest: The authors declare no conflict of interest.

\section{References}

1. Bhat, S.; Tiwari, P. Controllability of spacecraft attitude using control moment gyroscopes. IEEE Trans. Autom. Control 2009, 54, 585-590. [CrossRef]

2. Fang, J.; Ren, R. High-precision control for a single-gimbal magnetically suspended control moment gyro based on inverse system method. IEEE Trans. Ind. Electron. 2011, 58, 4331-4342. [CrossRef]

3. Cui, P.; Li, S. Suppression of Harmonic current in active-passive magnetically suspended CMG using improved repetitive controller. IEEE/ASME Trans. Mechatron. 2016, 63, 6962-6970. [CrossRef]

4. Han, B.; Zheng, S. Integral design and analysis of passive magnetic bearing and active radial magnetic bearing for agile satellite application. IEEE Trans. Magn. 2016, 21, 2132-2141.

5. Dhaouadi, R.; Ghorbel, F. A new dynamic model of hysteresis in harmonic drives. IEEE Trans. Ind. Electron. 2003, 50, 1165-1171. [CrossRef]

6. Chou, M.; Liaw, C. Dynamic control and diagnostic friction estimation for an SPMSM-driven satellite reaction wheel. IEEE Trans Ind. Electron. 2011, 58, 4693-4707. [CrossRef]

7. Han, S.; Lee, J. Friction and uncertainty compensation of robot manipulator using optimal recurrent cerebellar model articulation controller and elasto-plastic friction observer. IET Control Theory Appl. 2011, 5, 2120-2141. [CrossRef]

8. Verbert, K.; Toth, J. Adaptive friction compensation: A globally stable approach. IEEE/ASME Trans. Mechatron. 2016, 21, 351-363. [CrossRef]

9. Cui, P.; Zhang, D. Friction compensation based on time delay control and internal model control for gimbal system in MSCMG. IEEE Trans Ind. Electron. 2017, 64, 3798-3807. [CrossRef]

10. Li, H.; Zheng, S. Precise control for gimbal system of double gimbal control moment gyro based on cascade extended state observer. IEEE Trans Ind. Electron. 2017, 64, 4653-4661. [CrossRef]

11. Liu, T.; Huang, S. Cogging torque reduction by slot-opening shift for permanent magnet machines. IEEE Trans. Magn. 2013, 49, 4028-4031. [CrossRef]

12. Parsa, L.; Hao, L. Interior permanent magnet motors with reduced torque pulsation. IEEE Trans Ind. Electron. 2008, 55, 602-609. [CrossRef]

13. Chai, S.; Wang, L. A cascade MPC control structure for a PMSM with speed ripple minimization. IEEE Trans. Ind. Electron. 2013, 60, 2978-2987. [CrossRef]

14. Hu, X.; Li, H. Speed control for PMSM servo system using predictive functional control and extended state observer. IEEE Trans. Ind. Electron. 2012, 59, 1171-1183.

15. Flieller, D.; Nguyen, N. A self-learning solution for torque ripple reduction for nonsinusoidal permanent-magnet motor drives based on artificial neural networks. IEEE Trans. Ind. Electron. 2013, 61, 655-666. [CrossRef]

16. Qian, W.; Panda, S. Torque ripple minimization in PM synchronous motors using iterative learning control. IEEE Trans. Power Electron. 2004, 19, 272-279. [CrossRef]

17. Mattavelli, P.; Tubiana, L. Torque-ripple reduction in PM synchronous motor drives using repetitive current control. IEEE Trans. Power Electron. 2005, 20, 1423-1431. [CrossRef]

18. Eren, S.; Pahlevani, M. A digital current control technique for grid-connected AC/DC converters used for energy storage systems. IEEE Trans. Power Electron. 2017, 32, 3970-3988. [CrossRef]

19. Li, B.; Hang, L. Robust proportional resonant regulator for grid-connected voltage souce inverter (VSI) using direct pole placement design method. IET Power Electron. 2012, 5, 1367-1373. [CrossRef]

20. Teodorescu, R.; Blaabjerg, M. Proportional-resonant controller and filters for grid-connected voltage-source converters. IEE Proc. Electr. Power Appl. 2006, 153, 750-762. [CrossRef] 
21. Iacchetti, M.; Marques, G. Torque ripple reduction in a DFIF-DC system by resonant current controllers. IEEE Trans. Power Electron. 2015, 30, 4244-4254. [CrossRef]

22. Zeng, J.; Degobert, P. Minimum torque ripple control of permanent magnet synchronous motor in the stationary reference frame. In Proceedings of the IEEE International Conference on Electric Machines and Drives, San Antonio, TX, USA, 15-18 May 2005; pp. 667-673.

23. Yepes, A.; Francisco, F. Fernandez-Comesana, P. Torque ripple minimization in surface-mounted PM drives by means of PI + multi-resonant controller in synchronous reference frame. In Proceedings of the IECON 2010 Conference on IEEE Industrial Electronics Society, Melbourne, Australia, 7-10 November 2010; pp. 1017-1022.

24. Gao, J.; $\mathrm{Wu}, \mathrm{X}$. Torque ripple minimization of permanent magnet synchronous motor using a new proportional resonant controller. IET Power Electron. 2017, 10, 208-214. [CrossRef]

25. Xia, C.; Ji, B. Smooth speed control for low-speed high-torque permanent-magnet synchronous motor using proportional-integral-resonant controller. IEEE Trans Ind. Electron. 2015, 62, 2123-2134. [CrossRef]

26. Francis, B.; Wonham, W. The internal model principle of control theory. Automatica 1976, 12, 457-465. [CrossRef]

(C) 2018 by the authors. Licensee MDPI, Basel, Switzerland. This article is an open access article distributed under the terms and conditions of the Creative Commons Attribution (CC BY) license (http:/ / creativecommons.org/licenses/by/4.0/). 